\title{
PRESERVAÇÃO DOS RECURSOS HÍDRICOS E A LIMITAÇÃO REGULATÓRIA ADMINISTRATIVA DECORRENTE DA OUTORGA DE DIREITO DE USO DAS ÁGUAS SUBTERRÂNEAS NO BRASIL
}

\author{
PRESERVATION OF HYDRICAL RESOURCES AND THE \\ ADMINISTRATIVE REGULATORY LIMITATION ARISING OUT OF THE \\ GRANT OF USE RIGHTS OF UNDERGROUND WATERS IN BRAZIL
}

\begin{abstract}
Júlio César de Souza*
Sébastien Kiwonghi Bizawu**

Resumo: O presente artigo visa a abordar a orientação legislativa definida no tocante ao uso, manejo e apropriação dos recursos hídricos, a partir da análise do contexto histórico da evolução do reconhecimento da água como bem ambiental, público, finito e dotado de valor econômico, cuja utilização, disposição e acesso constituem-se em direito fundamental, a ser protegido por regulação e gestão ambiental. A análise crítica é situada especialmente no tocante à imposição do instrumento de política nacional de outorga do direito de uso das águas subterrâneas, em que se analisou, à luz da ponderação de interesses, o entendimento dos Tribunais Superiores quanto à prevalência da preservação da água sobre outros direitos. Para o desenvolvimento do estudo, foi utilizada uma abordagem qualitativa e natureza descritiva, tendo como norte metodológico o método dedutivo, por meio da técnica monográfica, com realização de revisão bibliográfica de artigos e obras doutrinárias nacionais referentes ao tema e análises de decisões.
\end{abstract}

Palavras-chave: Recursos hídricos; Legislação ambiental; Regulação; Outorga de uso; Ponderação de interesses.

\begin{abstract}
The present article aims to address the legislative orientation defined regarding the use, management and appropriation of water resources, based on the analysis of the historical context related to the evolution of the recognition of water as an environmental, public, finite and endowed with economic value, whose use, disposition and access constitute a fundamental right, to be protected through regulation and environmental management. The critical analysis is focused in particular on the imposition of the instrument of national policy for granting the right to use groundwater, in which, in light of the balance of interests, the Supreme Courts' understanding of the prevalence of water preservation over others rights. For the development of the study, a qualitative and descriptive approach was used, using the methodological approach as the deductive method, through the monographic technique, with the accomplishment of bibliographical revision of articles and national doctrinal works referring to the subject and analysis of
\end{abstract}

\footnotetext{
* Mestrando em Direito Ambiental e Sustentabilidade pela Escola Superior Dom Helder Câmara (ESDHC/MG). Bacharel em Direito e Especialista em Gestão Pública pela Universidade Federal de Ouro Preto (UFOP). Integrante do grupo de pesquisa: Regulação Ambiental da Atividade Econômica Sustentável (REGA)/CNPQ-BRA. E-mail: juliocesarufop@gmail.com.

** Doutor e Mestre em Direito Internacional pela Pontifícia Universidade Católica de Minas Gerais (PUC Minas). Professor de Direito Internacional Público e Privado na Escola Superior Dom Helder Câmara (ESDHC). Pró-Reitor do Programa de Pós-Graduação em Direito ESDHC/MG. E-mail: kiwonghi@domhelder.edu.br.
} 
Preservação dos recursos hídricos e a limitação regulatória administrativa decorrente da outorga de direito de uso das águas subterrâneas no Brasil

decisions.

Keywords: Water resource; Legislation; Regulation; Grant of use; Weighting of interests.

\section{INTRODUÇÃO}

A água, por sua natureza essencial, permanentemente se constituiu como fator de grande preocupação para a humanidade, sendo objeto de uso, proteção e desejo de apropriação.

De acordo com dados da Organização das Nações Unidas (2010), estima-se que mais de um bilhão de pessoas em todo o mundo enfrente alguma dificuldade relacionada à escassez e/ou à contaminação dos recursos hídricos consumíveis. São pessoas carentes de acesso a um abastecimento de água suficiente para atender necessidades básicas de suporte a uma vida digna ${ }^{1}$.

Destarte, o crescimento populacional exponencial, aliado ao avanço dos níveis e meios de produção nas mais diversas áreas, especialmente nas searas agrícola e industrial, tem gerado forte pressão sobre os recursos hídricos e a sua disponibilidade finita, circunstâncias que demandam posturas globais ainda mais associadas à preservação da água e otimização consciente de seu uso.

Assim, a água e sua indispensabilidade inerente à condição humana tornam esse bem ambiental de extrema relevância, garantindo-lhe acentuada importância no âmbito das diretrizes de políticas de gestão ambiental dos recursos hídricos.

Logo, tem-se debatido a necessidade de se condicionar as decisões relativas ao uso e aproveitamento dos recursos hídricos a um complexo de proposições com o intuito de salvaguardar o bem ambiental, sem, contudo, impedir o efetivo acesso a ele, para consolidar as mais diversas atividades ligadas ao desenvolvimento humano.

Dentre os países detentores de recursos ambientais, o Brasil é considerado a maior potência hídrica do mundo. Possui cerca de $13 \%$ da água doce existente no globo terrestre, com grandes perspectivas de aproveitamento desse bem ambiental nos mais diversos campos, tais como consumo interno individual e coletivo, aproveitamento hidrelétrico, uso para fins de plantio agrícola e na pecuária, aplicações industriais, dentre outros $^{2}$.

Esse privilégio na abundância dos recursos hídricos obrigou a nação a priorizar a produção de instrumentos normativos aptos a desenvolverem uma política ambiental, tendo como finalidade a preservação, controle, equacionamento e 
racionalização do uso e utilidade da água doce existente.

Nesse contexto, é necessário que as regras estabelecidas para o uso da água, bem finito, gozem de natureza cogente, de modo a ser factível a oposição de diretrizes limitadoras e cuja restrição signifique controle das condutas de uso e apropriação da água.

Para tanto, a Política Nacional de Recursos Hídricos estabeleceu regras de sustentabilidade visando à conservação de tais recursos, instituindo limitações administrativas cuja finalidade é mitigar o uso abusivo, ineficiente ou inadequado da água.

No tocante às águas subterrâneas, verifica-se que a Lei n. ${ }^{\circ}$ 9.433/97 fixou as diretrizes para a atuação do gestor ambiental, estabelecendo a obrigatória outorga de seu uso e trazendo para o ordenamento jurídico nacional a necessidade de submissão de todos os instrumentos de controle de uso dos recursos hídricos dessa natureza.

Por outro lado, grande tem sido a controvérsia verificada no cômputo das decisões judiciais atinentes à temática da utilização dos recursos hídricos, especialmente as relativas às águas subterrâneas acessíveis ao consumo humano.

Assim, o objetivo do presente artigo é analisar o processo histórico que concedeu aos recursos hídricos a importância no campo normativo da gestão ambiental, bem como compreender a legislação vigente referente à proteção e preservação da água, enquanto bem ambiental de domínio público, finito e dotado de valor econômico.

Destarte, é forçoso analisar o comportamento do Superior Tribunal de Justiça (STJ) em relação ao aparente conflito de direitos fundamentais no tocante à fruição e apropriação dos recursos hídricos.

Nesse contexto, questiona-se: como se manifesta o STJ em relação aos aparentes conflitos envolvendo a fruição e a apropriação dos recursos hídricos?

Desse modo, será necessário verificar os condicionamentos ao uso das águas subterrâneas e o aproveitamento nos âmbitos legislativo e administrativo. Por fim, objetiva-se analisar o posicionamento dos tribunais brasileiros no tocante ao conflito de interesses individuais, econômicos e ambientais atinentes à utilização da água.

Nota-se que o tema proposto é relevante na medida em que se propõe a perscrutar a necessária relação entre o uso, o consumo, a necessidade e a preservação da água doce, bem ambiental escasso nas mais diversas regiões do planeta, cuja demanda global aumenta gradativamente.

Consequentemente, é imprescindível o estudo do aparato legislativo definidor das políticas regulatórias de gestão do uso da água no país, bem como da resposta R. Fac. Dir. UFG, v. 41, n. 3, p.184-205, set/dez. 2017 
Preservação dos recursos hídricos e a limitação regulatória administrativa decorrente da outorga de direito de uso das águas subterrâneas no Brasil

jurisprudencial aos conflitos decorrentes das mais diversas necessidades de utilização dos recursos hídricos existentes em solo nacional.

Para o desenvolvimento do estudo, foi utilizada abordagem qualitativa e natureza descritiva, tendo como norte metodológico o método dedutivo, por meio da técnica monográfica, com realização de revisão bibliográfica de artigos e obras doutrinárias nacionais referentes ao tema e análises de decisões.

\section{EVOLUÇÃO HISTÓRICA DA PROTEÇÃO DOS RECURSOS HÍDRICOS}

A humanidade contou com o uso da água no curso do seu desenvolvimento. As primeiras civilizações de que se tem notícia evolutiva estiveram atreladas a locais ricos em recursos hídricos e se utilizaram dos seus potenciais de consumo e abastecimento, indispensáveis ao desempenho eficiente das atividades econômicas.

Rios como Tigre e Eufrates, na Mesopotâmia, Nilo no Egito, Amarelo na China e Ganges na Índia (COSTA e TYBSCH, 2015), em suas peculiaridades, foram grandes responsáveis pelo avanço civilizatório das regiões referidas, cujo período de degradação coincide com o declínio de algumas das comunidades antigas.

Assim, verifica-se que o crescimento civilizatório caminhou em parceria com a exploração dos recursos naturais existentes em abundância, dos quais a água é, atualmente, elemento fundamental ao desempenho bem-sucedido do incremento econômico nos mais diversos setores.

A expansão de sua exploração ocorreu progressivamente, acentuando-se durante o período denominado Revolução Industrial, no século XVIII, circunstância ocorrida sem o controle necessário dos países. Tal fato foi objeto de observação e preocupação internacional somente no ano de 1972, a partir da realização da Conferência das Nações Unidas, em Estocolmo, Suécia.

É a partir da década de 70, durante o século XX, que os temas meio ambiente, preservação dos recursos naturais e, mais especificamente, água ganham contornos de relevância conceitual, sendo o referido bem natural erigido à condição de tema estratégico no Programa das Nações Unidas para o Meio Ambiente (BARBOSA, 2011).

É válido ainda referenciar a realização da primeira Conferência sobre água, ocorrida na cidade de Mar Del Plata, Argentina, no ano de 1977, cujo indicativo referiase ao reconhecimento da existência de uma crise hídrica de proporção mundial, onde supostas alternativas foram discutidas e inseridas no Plano de Ação de Mar Del Plata 
(BARBOSA, 2011).

Em 1992, a ONU realizou a Conferência Internacional sobre Água e Meio Ambiente, na cidade de Dublin, Irlanda, sucedida pela Conferência das Nações Unidas sobre Meio Ambiente e Desenvolvimento (Eco 92), na cidade do Rio de Janeiro, Brasil, cujos avanços se deram no âmbito das propostas contidas na denominada Agenda 21. Nesta, foram delimitadas algumas áreas para desenvolvimento de programas específicos no campo da proteção da qualidade e do abastecimento dos recursos hídricos, com a definição de necessária aplicação de critérios integrados ao incremento, manejo e uso da água doce (BARBOSA, 2011).

No ano de 2010, a Organização das Nações Unidas reconheceu, por meio da Resolução A/RES/64/292, a água limpa e segura como direito humano fundamental à vida de todos.

Tal reconhecimento se deu em decorrência da grave crise hídrica, permanente em locais específicos no contexto internacional, e da constatação da possibilidade verossímil de enfrentamento de escassez de água em todo o mundo, se não forem modificados os padrões de desenvolvimento econômico e as condutas individuais de uso e consumo da água, tendo em vista que a água doce representa somente $2,9 \%$ do complexo hídrico mundial, onde 2,1\% encontra-se em estado sólido na região das calotas polares (Souza 2012).

No Brasil, a temática relacionada aos recursos hídricos ingressou no ordenamento jurídico mediante edição do Decreto n. ${ }^{\circ} 24.643$, de 1934, intitulado Código das Águas. Contudo, após a promulgação da Constituição da República de 1988 (CF/88), o referido dispositivo legal não foi inteiramente recepcionado e, após, parcialmente revogado pela Lei $n .^{\circ}$ 9.433/97.

A referida Lei instituiu no país a política nacional de recursos hídricos, sendo, portanto, um marco importante na regulamentação da temática no Brasil. Posteriormente foram editadas as Leis n. ${ }^{\circ}$ 9.984/2000 e 11.445/2007, criando respectivamente a autarquia especial Agência Nacional das Águas e a política de tratamento de resíduos de esgotamento sanitário como será visto a seguir.

\section{POLÍTICAS E INSTRUMENTOS LEGISLATIVOS DE PROTEÇÃO DOS RECURSOS HÍDRICOS}

Os recursos hídricos no Brasil são dotados de arcabouço jurídico qualificado, 
Preservação dos recursos hídricos e a limitação regulatória administrativa decorrente da outorga de direito de uso das águas subterrâneas no Brasil

com o fim de garantir a proteção, gestão, controle e monitoramento do uso e manejo das águas, bem público, limitado, de valor econômico, regido pelos princípios preservacionistas do acesso equitativo dos recursos naturais e da intervenção estatal compulsória, em razão da necessidade de salvaguarda desse bem ambiental essencial às presentes e futuras gerações.

A questão ambiental ganhou evidência e força normativa com a inauguração de uma nova ordem constitucional a partir de 5 de outubro de 1988, em que o meio ambiente foi elevado à categoria de direito fundamental, a ser protegido e usufruído por toda a sociedade.

No texto constitucional, a preservação da biota foi erigida como diretriz a ser seguida pelas atividades empreendidas e acolhida pela manifestação social coletiva, destinatária dos direitos elencados no art. 225, conforme disposto a seguir:

Art. 225. Todos têm direito ao meio ambiente ecologicamente equilibrado, bem de uso comum do povo e essencial à sadia qualidade de vida, impondo-se ao Poder Público e à coletividade o dever de defendê-lo e preservá-lo para as presentes e futuras gerações. [...] (BRASIL, 1988).

No que concerne aos recursos hídricos, verifica-se que a Constituição da República de 1988 estabeleceu regras de competência legislativa sobre o tema, instituiu a Política Nacional dos Recursos Hídricos e dimensionou os critérios de outorga de uso da água, conforme elencam os artigos 20, 21 e 26, a seguir (BARBOSA, 2011):

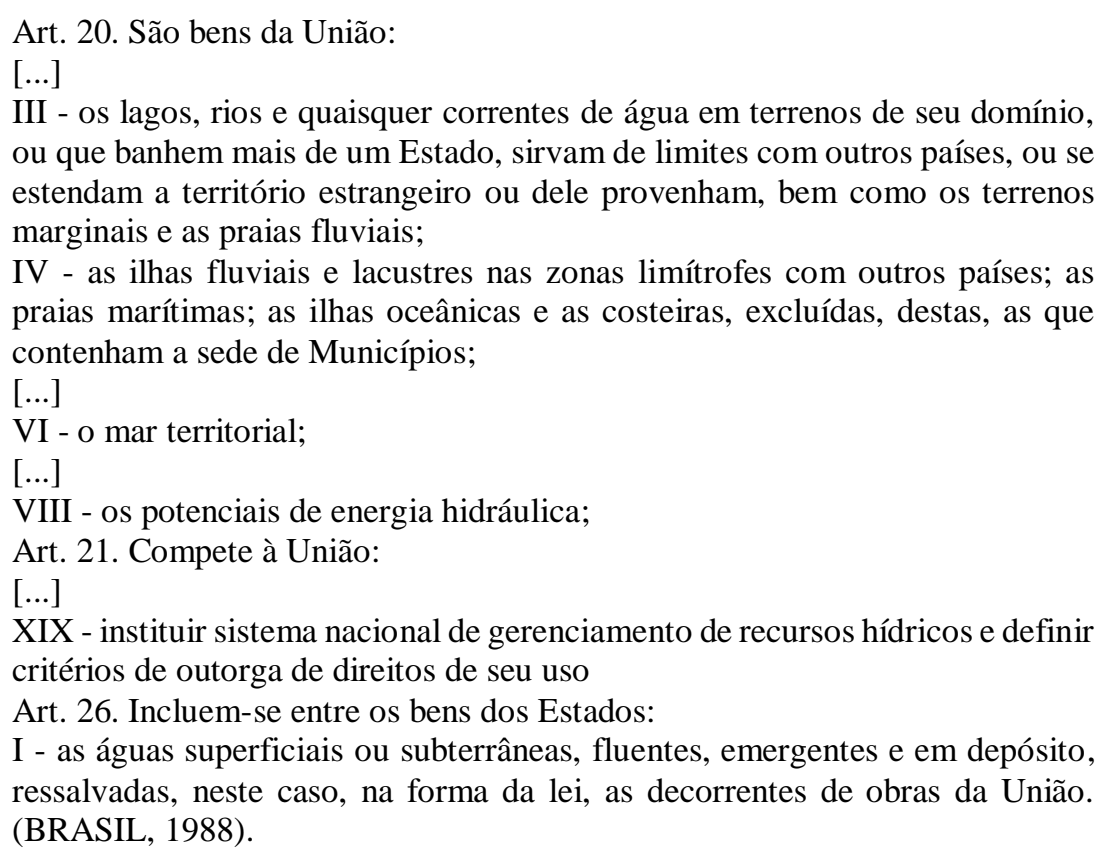

Sobre os artigos previstos na Constituição da República de 1988, elencados 
anteriormente, nota-se que o constituinte, com a intenção de preservar a participação dos entes da Federação nos métodos de utilização e manejo dos recursos hídricos, estipulou normas de competência legislativa de vasta abrangência, conforme pontuado por Fiorillo:

[...] diante dessa celeuma, em que não restou claro ser competência da União legislar sobre a matéria água ou caber a ela somente a edição de normas gerais, temos que a melhor interpretação é extraída com base no art. 24, de modo que a competência para legislar sobre normas gerais é atribuída à União, cabendo aos Estados e ao Distrito Federal legislar complementarmente e ao Município suplementarmente, com base no art. 30, II, da Constituição Federal (FIORILLO, 2012, p. 305).

Conforme previsão contida no inciso XIX do art. 21 da CR/88, foi instituída, em 8 de janeiro de 1997, a Política Nacional de Recursos Hídricos, mediante entrada em vigor da Lei n. ${ }^{\circ}$ 9.433/97. A finalidade da Lei atrelou-se ao necessário balizamento de regras consagradoras dos princípios da intervenção estatal compulsória, do acesso equitativo à água, da natureza pública da proteção ambiental e do desenvolvimento sustentável, com a necessária observância legal das diretrizes da descentralização, controle, participação e integração das políticas públicas desenvolvidas no âmbito dos recursos hídricos.

A Lei das Águas apresenta em seus dispositivos a orientação legislativa que prioriza valores ambientais e sociais a serem obrigatoriamente observados por todos os partícipes do processo de uso e apropriação dos recursos hídricos, destacando em seus objetivos o respeito à aplicação do princípio da equidade intergeracional.

O comando legal delimita ainda as formas de uso da água, versando que a utilização da água deve obedecer a fatores determinados de oferta de qualidade adequada, a ser realizada de modo racional, garantindo-se inclusive a multiplicidade de oportunidades de utilização nas mais diversas atividades. Além disso, deve assegurar a proteção de tais recursos a partir da instituição de políticas públicas de prevenção de danos ao patrimônio hídrico nacional.

Consoante leciona Barbosa (2011), o país inaugurou pós-Constituição de 1988, especialmente na década de 90 do século XX, um novo momento relacionado a uma visão ecocentrada, cuja diretriz se vinculou à necessidade de preservação do meio ambiente aliada às políticas de gestão, priorizando o gerenciamento compartilhado entre os diversos atores sociais usuários dos recursos hídricos. Nesse sentido são as ponderações do citado autor:

[...] o modelo brasileiro de gestão dos recursos hídricos, pontual-corretivo, 
Preservação dos recursos hídricos e a limitação regulatória administrativa decorrente da outorga de direito de uso das águas subterrâneas no Brasil

começou a ceder espaço para novas formas de gestão, porque as questões hídricas tornaram-se prioridades nas agendas de desenvolvimento. Dessa maneira, a gestão deverá ser compartilhada entre o Estado, a sociedade civil, o setor privado e as comunidades locais, por meio de uma democracia participativa e de decisões descentralizadas. (BARBOSA, 2011, p. 256).

Dentre as diretrizes gerais de ação da Lei n. ${ }^{\circ}$ 9.433/97, cumpre destacar a priorização pelo mote da gestão dos recursos hídricos e do plano das bacias hidrográficas, em consonância com a integração entre os demais setores de gestão ambiental, inclusive no planejamento, com a inserção e participação dos setores econômicos e dos usuários (BRASIL, 1997).

O Sistema Nacional de Recursos Hídricos é composto por instrumentos que contribuem para a realização das metas estabelecidas na Lei das Águas, dando efetividade ao conteúdo dos princípios que regem a Política Nacional e assegurando a execução de medidas de planejamento, fiscalização e contenção do uso das águas. Isso a fim de que a disponibilidade de tal bem cumpra sua missão socioambiental, sem que haja risco de degradação ou perda do recurso natural mencionado.

Tais mecanismos constituem-se na implementação do Plano Nacional dos Recursos Hídricos: o enquadramento dos corpos de água em classes, segundo seus usos preponderantes; a cobrança pelo uso de recursos hídricos e seu próprio Sistema Nacional de Informações; bem como a outorga dos direitos de uso dos recursos hídricos, esta a ser examinada no decorrer do estudo.

Outra importante inovação legislativa diz respeito à edição da Lei $\mathrm{n}^{\circ}$ 9.984/2000, que instituiu a autarquia especial Agência Nacional das Águas (ANA) ${ }^{3}$, relevante mecanismo de controle administrativo cuja finalidade é regular as atividades que necessitam de utilização dos recursos hídricos, a fim de formular normativa específica, bem como estabelecer metodologias de fiscalização e aplicação do poder de polícia.

Essa agência reguladora foi criada no momento em que o país optava por um novo modelo de gestão administrativa que eximia o Estado da realização de atividades anteriormente desempenhadas.

Contudo, ainda que se tome por base a nova perspectiva estatal em definir como meta de gestão pública ausentar-se do comando e controle direto de diversas áreas e atividades, houve o reconhecimento da patente e a necessária obrigação do Estado de manter-se envolvido com as demandas sensíveis ao interesse público, tendo em vista sua natureza e finalidade essenciais ${ }^{4}$. 
A previsão constitucional desse relevante instrumento de ordenação legislativa e executória encontra guarida no art. 174, caput, da Lei Fundamental de 1988, conforme disposto a seguir: "Art. 174. Como agente normativo e regulador da atividade econômica, o Estado exercerá, na forma da lei, as funções de fiscalização, incentivo e planejamento, sendo este determinante para o setor público e indicativo para o setor privado" (BRASIL, 1988).

Tal proteção legislativa denota que agência reguladora ${ }^{5}$ competente deve tutelar a água - bem de domínio público dotado de valor econômico -, editando normativa e organizando os eixos da fiscalização necessária a contribuir com as boas práticas legislativas.

Em termos de legislação regulamentar e atinente às águas, o Brasil dispõe do

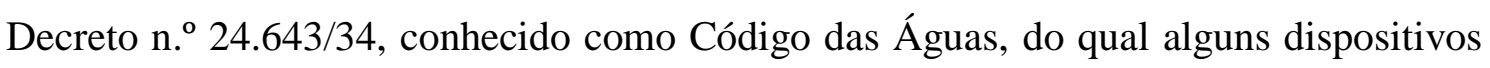
ainda estão em vigor, haja vista que, com a inauguração da nova ordem constitucional de 1988 e suas posteriores leis infraconstitucionais, a temática dos recursos hídricos ganhou viés principiológico inovador incompatível com as disposições do referido Decreto.

Por fim, os recursos hídricos também foram objeto de regulamentação no Código Civil de $2002^{6}$ e na Lei n. ${ }^{\circ} 11.445 / 2007^{7}$, a qual traz importante aperfeiçoamento legislativo concernente à exploração de águas subterrâneas, tratada de modo mais particularizado a seguir.

\section{REGULAÇÃO ADMINISTRATIVA MEDIANTE OUTORGA DE DIREITO DO USO DOS RECURSOS HÍDRICOS}

O Estado brasileiro ${ }^{8}$, com o fim de executar o anseio coletivo materializado na legislação pátria de modo a garantir o regramento contido no ordenamento jurídico interno e internacional (nos casos em que o Brasil é signatário), pode interferir na atividade privada para assegurar o desenvolvimento de políticas públicas que reflitam os fundamentos, objetivos, princípios e regras integrantes da diretriz nacional de tutela do interesse público.

Sendo assim, o Estado, como ente político e jurídico, é incumbido de promover intervenção na autonomia privada, de modo a propiciar a limitação das liberdades, adotando todos os meios lícitos possíveis, efetivos e coercitivos para garantir o enquadramento de todos à normativa vigente.

Nesse escopo, a legislação brasileira concede ao Estado a prerrogativa de R. Fac. Dir. UFG, v. 41, n. 3, p.184-205, set/dez. 2017 
Preservação dos recursos hídricos e a limitação regulatória administrativa decorrente da outorga de direito de uso das águas subterrâneas no Brasil

intervir no uso e manejo de bens passíveis de apropriação e regulá-los, submetendo atividades e pessoas ao desenvolvimento e alcance de suas funções sociais, assim como as condicionando à observância e realização do interesse público.

Para tanto, muitas são as modalidades de intervenção estatal no âmbito do domínio público, inclusive com o uso de mecanismos de autocontrole e também na seara privada, estendendo-se essas intervenções até mesmo à propriedade particular. Essas restrições foram criadas com base nos fundamentos da supremacia do interesse coletivo.

No caso específico dos recursos hídricos, em que pese a água seja definida legalmente como bem ambiental de domínio público, por muito tempo sua regulamentação foi insatisfatória, fato que gerou a necessidade de novo enquadramento constitucional, aliado a uma legislação infraconstitucional apta a solucionar conflitos e a conceder autorização de uso e manejo dos recursos hídricos.

Nesse sentido,

[...] esta lacuna foi preenchida com a edição da Lei Federal n ${ }^{\circ} 9.433$, de 10 de janeiro de 1997, que trouxe a previsão da outorga de direito de uso de recursos hídrico, objetivando assegurar o controle quantitativo e qualitativo dos usos da água e o efetivo exercício dos direitos de acesso à água. [...] (COSTA e TYBUSCH, 2015, p. 7).

A Lei n. ${ }^{\circ}$ 9.433/97 preconiza, em seu art. 12, os usos de recursos hídricos dependentes de outorga:

\footnotetext{
Art. 12. Estão sujeitos a outorga pelo Poder Público os direitos dos seguintes usos de recursos hídricos:

I - derivação ou captação de parcela da água existente em um corpo de água para consumo final, inclusive abastecimento público, ou insumo de processo produtivo;

II - extração de água de aquífero subterrâneo para consumo final ou insumo de processo produtivo;

III - lançamento em corpo de água de esgotos e demais resíduos líquidos ou gasosos, tratados ou não, com o fim de sua diluição, transporte ou disposição final;

IV - aproveitamento dos potenciais hidrelétricos;

$\mathrm{V}$ - outros usos que alterem o regime, a quantidade ou a qualidade da água existente em um corpo de água. (BRASIL, 1997).
}

Quanto à competência regulatória, conforme previsão contida no inciso IV do art. $4^{\circ}$ da Lei $n^{\circ}$ 9.984/2000, cabe à Agência Nacional de Águas outorgar, mediante autorização, o direito de uso de recursos hídricos em corpos de água de domínio da União, restando também sob sua gestão a obrigatoriedade de licença preventiva ${ }^{9}$ (BRASIL, 2000). Também é competência da ANA a emissão da reserva de disponibilidade hídrica para fins de aproveitamentos hidrelétricos e sua consequente conversão em outorga de 
direito de uso de recursos hídricos.

No âmbito estadual, semelhantes são as atribuições do estado-membro como parte integrante da tutela dos recursos hídricos. Ressaltem-se, dentre as políticas de gestão de recursos hídricos, as importantes atribuições dos estados federados em promoverem a gestão desses recursos no seu âmbito de atuação.

A eles também compete o dever de estabelecerem suas próprias instituições de controle de outorga, haja vista serem detentores, nos moldes da legislação de regência, de boa quantidade das águas, estando os municípios excluídos dessa pertença.

Machado enfatiza que os dispositivos legais relativos à gestão e preservação dos recursos hídricos devem ser recepcionados e obedecidos pela ação governamental federal e estadual na outorga de direitos de uso, em virtude da natureza vinculante de seu conteúdo, asseverando ainda que “[...] os Governos não podem conceder ou autorizar usos que agridam a qualidade e quantidade das águas, assim como não podem agir sem equidade ao darem acesso à água" (MACHADO, 2009, p. 471).

As normas estabelecidas com o fito de garantir a distribuição e o acesso equânime à água para as mais diversas utilidades consolidam o importante fundamento de serem os recursos hídricos bens públicos de uso comum. Por conseguinte, as ações de controle, supervisão e fiscalização desse bem ambiental escasso e limitado confirmam, especialmente quanto à captação, a impossibilidade de qualquer apropriação indevida para fins econômicos de acumulação de riqueza.

O enfoque sob o qual é visto o bem jurídico água é mudado, deixando o acesso à água de ser entendido como uma finalidade de apropriação de interesse privado, mas sim como direito fundamental necessário à sadia qualidade de vida da população.

Destarte, o comando legislativo constitucional e as leis atinentes à regulamentação do tema outorga de uso de água delimitam regras de modo a promover uma gestão da política pública de manejo dos recursos hídricos, pautando as condutas dos usuários desse bem com base em entendimento coletivo de gozo e fruição da água disponível.

Nesse contexto, a extração de água de aquífero subterrâneo para consumo final ou insumo de processo produtivo - uma das formas de utilização da água que exige a emissão de outorga de direito de uso de recursos hídricos - é objeto de grande debate no cenário jurídico.

A mudança de paradigma trazida pela $\mathrm{CF} / 88$ e leis infraconstitucionais posteriores colocou em evidência a utilização de recursos hídricos do subsolo e causa na R. Fac. Dir. UFG, v. 41, n. 3, p.184-205, set/dez. 2017 
Preservação dos recursos hídricos e a limitação regulatória administrativa decorrente da outorga de direito de uso das águas subterrâneas no Brasil

atualidade inconformismo em muitos defensores da diminuição do rigor para a permissão de acesso e apropriação dessa modalidade de disposição da água.

De acordo com os artigos $2^{\circ}$ e $3^{\circ}$ da Resolução n. ${ }^{\circ}$ 396/2008, as águas subterrâneas são definidas como águas que correm natural ou artificialmente no subsolo e são classificadas em seis classes que estabelecem parâmetros entre si de adequação e disponibilidade para os usos múltiplos, conforme suas características específicas (Conama 2008).

Assim é que, por meio desses parâmetros relacionados às características, quantidade, qualidade, vocação para o uso e intervenção antrópica, a ANA e as agências e órgãos de regulação estaduais avaliam os pedidos de outorga de direito de uso das águas subterrâneas.

Além da normativa devidamente mencionada, faz-se necessário indicar a íntima relação entre a preservação das águas subterrâneas e a política de saneamento básico, uma vez que o sucesso de implementação desta pressupõe a sobrevivência e manutenção dos recursos hídricos.

Em razão dessa simbiose, a Lei n. ${ }^{0} 11.445 / 2007$ trouxe em seus dispositivos a vedação de utilização de fontes alternativas de fornecimento de água em locais atendidos pela rede pública de abastecimento, conforme se verifica da dicção do art. 45 , $\S \S 1^{\mathrm{o}}$ e $2^{\mathrm{o}}$ :

Art. 45. Ressalvadas as disposições em contrário das normas do titular, da entidade de regulação e de meio ambiente, toda edificação permanente urbana será conectada às redes públicas de abastecimento de água e de esgotamento sanitário disponíveis e sujeita ao pagamento das tarifas e de outros preços públicos decorrentes da conexão e do uso desses serviços.

$\S 1^{\circ} \mathrm{Na}$ ausência de redes públicas de saneamento básico, serão admitidas soluções individuais de abastecimento de água e de afastamento e destinação final dos esgotos sanitários, observadas as normas editadas pela entidade reguladora e pelos órgãos responsáveis pelas políticas ambiental, sanitária e de recursos hídricos.

§ 2을 A instalação hidráulica predial ligada à rede pública de abastecimento de água não poderá ser também alimentada por outras fontes. (BRASIL, 2007).

Tais dispositivos legais contidos na Lei de Saneamento Básico ${ }^{10}$ têm sido objeto de questionamento judicial, por supostamente violarem princípios consumeristas de liberdade de escolha quanto ao abastecimento de que irão se utilizar pessoas físicas e jurídicas, bem como por irem de encontro ao estatuído no antigo Código das Águas e no Código Civil em vigor.

Além das Leis gerais n. 9.433/97, 9.984/2000 e 11.445/2007, tem sido 
tendência entre os estados a edição de atos normativos regulamentares, disciplinando regras restritivas a serem observadas pelos órgãos reguladores do processo de emissão de outorgas de uso de águas subterrâneas.

Um exemplo de regulamentação estadual, normalmente realizada mediante Decreto, versa sobre a permissibilidade da outorga de direito de uso de águas subterrâneas em localidades alcançadas pela rede de abastecimento. Os estados, a partir de uma concepção regulatória, intensificada pelos comandos legais existentes, têm reiteradamente preservado a natureza pública compulsória que perpassa o fornecimento de água potável e proibido o uso alternativo de outras fontes e coletas de recursos hídricos onde há abastecimento regular.

Tais posicionamentos corroboram a principiologia contida nas Leis $\mathrm{n}^{\circ}$ 9.433/97 e 11.445/2007, com o intuito, a princípio, de preservar o meio ambiente e assegurar a qualidade da oferta de água e por consequência evitar problemas de saúde pública, bem como priorizar o uso racional dos recursos hídricos, evitando implicações nefastas à manutenção e desenvolvimento da rede de saneamento básico.

Contudo, a previsão legal elencada na Lei n. ${ }^{\circ}$ 11.445/2007, aliada à opção dos gestores ambientais, tem, ao longo dos últimos anos, causado grandes conflitos de interesses, atingindo desde os indivíduos desejosos de armazenamento de água para consumo próprio, até os diversos ramos do setor econômico, agrícola e industrial situados em locais com abastecimento de água pela rede de saneamento.

\section{A POLÍTICA dOS RECURSOS HídRICOS E A JUDICIALIZAÇÃo DO USO DAS ÁGUAS SUBTERRÂNEAS}

Essa problemática instiga a premissa a ser debatida: a água é bem ambiental de domínio público, passível de finitude e dotado de valor econômico.

A legislação de regência sobre essa temática recepcionou a natureza pública do bem jurídico água, definição encontrada em toda a legislação recepcionada pela $\mathrm{CR} / 88$.

Na seara judicial, a natureza jurídica do bem água e os limites ao seu uso já foram alvo de manifestação do Poder Judiciário, inclusive do Superior Tribunal de Justiça, que, por sua vez, consolidou a primazia do caráter público dos recursos hídricos, conforme apontado a seguir: 
Preservação dos recursos hídricos e a limitação regulatória administrativa decorrente da outorga de direito de uso das águas subterrâneas no Brasil

[...].

2. As águas em estado natural são bens públicos e só podem ser explorados por particulares mediante concessão, permissão ou autorização. 3. A água, portanto, fornecida à população, após ser tratada pelas empresas concessionárias, permissionárias ou autorizadas, não caracteriza mercadoria. (REsp 794.984/RJ, Primeira Turma. Rel. Min. José Delgado. Julg: 5.9.2006. DJ, 5 set. 2006).

Tal entendimento expõe a predileção pela preservação desse recurso natural, em detrimento da vontade desenfreada de seu aproveitamento econômico, visando compatibilizar as vontades individuais com a necessária prevalência do interesse público da proteção da água para a coletividade presente e futura.

Nesse sentido é esclarecedor o julgado do Superior Tribunal de Justiça:

[...] A água é bem público de uso comum (art. $1^{\circ}$ da Lei $n^{\circ}$ 9.433/97) motivo pelo qual é insuscetível de apropriação pelo particular. 5. O particular tem, apenas, o direito à exploração das águas subterrâneas mediante autorização do Poder Público, cobrada a devida contraprestação (arts. 12, II, e 20 da Lei ${ }^{\circ}$ 9.433/97). 6. Ausente a autorização para exploração a que alude o art. 12 da Lei $n^{\circ} 9.433 / 97$, atentando-se para o princípio da justa indenização, revela-se ausente o direito à indenização pelo desapossamento do aquífero. (REsp n ${ }^{\circ}$ 518.744/RN, Primeira Turma. Rel. Min. Luiz Fux. Julg: 3.2.2004.DJ, 25 fev. 2004).

Todavia, em que pese o entendimento jurisprudencial indicado, ainda resta a circunstância litigiosa de embate entre o gestor público dos recursos hídricos e os demais interessados no uso das águas subterrâneas em locais com acesso a rede de abastecimento, estes amparados por decisões dos Tribunais dos Estados, que entendiam ilegal o impedimento de captação de água subterrânea para consumo humano, mesmo nas localidades referidas.

À guisa de exemplo, cumpre destacar a ementa do Tribunal de Justiça do Rio Grande do Sul transcrita abaixo, citada no voto do Relator do Recurso Especial no STJ:

APELAÇÃO CÍVEL. PEDIDO DE OUTORGA DE EXTRAÇÃO DE ÁGUA DE POÇO ARTESIANO PARA FINS DE CONSUMO HUMANO. NEGATIVA A PRETEXTO DE A LEGISLAÇÃO CONTEMPLAR APENAS PARA FINS INDUSTRIAIS, DE FLORICULTURA E AGRICULTURA. DECISÃO QUE CONTRARIA JURISPRUDÊNCIA E ATÉ MESMO PARECER DA PROCURADORIA GERAL DO ESTADO. TODAVIA, PRETENSÃO INICIAL QUE MERECE ACOLHIDA SOMENTE EM PARTE, ISTO É, UMA VEZ AFASTADO O FUNDAMENTO DA DECISÃO ADMINISTRATIVA, SER ORDENADO PROSSIGA O RESPECTIVO PROCESSO. A FIM DE VERIFICAÇÃO DO CUMPRIMENTO DOS DEMAIS REQUISITOS. NÃO É POSSÍVEL, NAS CIRCUNSTÂNCIAS, ORDENAR SEJA EXPEDIDA A OUTORGA DE EXPLORAÇÃO. POR MAIORIA, APELAÇÃO PROVIDA EM PARTE (fl. 277). (Tribunal de Justiça do Rio Grande do Sul, 2012). 
A referida decisão foi objeto de Recurso Especial interposto ao Superior Tribunal de Justiça, que, por sua vez, decidiu recentemente a contenda de modo esclarecedor, consolidando a posição da jurisprudência pátria em relação ao tema, conforme se extrai da ementa do acórdão a seguir:

PROCESSUAL CIVIL E ADMINISTRATIVO. VIOLAÇÃO ART. 535 DO CPC/73. INOCORRÊNCIA. EXTRAÇÃO DE ÁGUA SUBTERRÂNEA. POÇO ARTESIANO. OUTORGA DA ADMINISTRAÇÃO PÚBLICA. TUTELA DO INTERESSE COLETIVO EM DETRIMENTODO PARTICULAR. LEGALIDADE DA LIMITAÇÃO ADMISTRATIVA PARA UTILIZAÇÃO DE POÇO ARTESIANO COM A FINALIDADE DE CONSUMO HUMANO DE ÁGUA POTÁVEL.

I - Trata-se, na origem, de ação ordinária julgada improcedente, ao se objetivada a outorga e autorização para utilização de poço artesiano para consumo humano de água subterrânea. Em apelação, acolheu-se em parte o pedido para o prosseguimento do procedimento administrativo, a fim de que se verificasse o cumprimento dos demais requisitos por parte da autora, ora recorrida.

II - Não há violação ao artigo 535 do CPC/73 quando o Tribunal de origem, ao apreciar a demanda, manifestou-se sobre todas as questões pertinentes a litis contestatio, fundamentando seu proceder de acordo com os fatos apresentados e com a interpretação dos regramentos legais que entendeu aplicáveis, demonstrando as razões de seu convencimento.

III - Ao fixar as normas gerais, por se tratar de questão de política ambiental, a União tutelou o interesse coletivo em detrimento do particular, estabelecendo, inclusive, textualmente, que as edificações permanente urbanas devem estar conectadas às redes públicas de abastecimento de água e que a respectiva instalação hidráulica predial não pode ser alimentada por outras fontes.

IV - Não pode ser considerada ilegal a limitação administrativa estabelecida pelo recorrente no sentido de que, nos locais dotados de rede de abastecimento de água potável, os poços serão tolerados exclusivamente para suprimento com fins industriais ou para uso em floricultura ou agricultura.

$\mathrm{V}$ - Recurso Especial provido para julgar improcedente o pedido formulado pela recorrida na petição inicial da demanda. (REspn ${ }^{\circ}$ 1.345.403-RS, Segunda Turma. Rel. Min. Francisco Falcão. Julg: 16.1.2017).

Alguns aspectos relevantes relativos ao direito material de cunho principiológico merecem análise, pois a decisão confirma a eficácia da legislação federal em vigor. Ademais, o julgado materializa a efetividade do conceito de água como bem ambiental público, de uso comum, finito e dotado de valor econômico, a ser fruído adequadamente pelas presentes e futuras gerações, nas mais diversas atividades relativas ao consumo humano.

A posição do Superior Tribunal de Justiça é fundamentada em pressupostos de direito material salvaguardados pela $\mathrm{CR} / 88$, na medida em que consagra a aplicação de princípios de direito ambiental reconhecedores da visão jurídica da água como direito fundamental inalienável.

Nesse aspecto, a decisão do referido Tribunal Superior contempla a afirmação 
Preservação dos recursos hídricos e a limitação regulatória administrativa decorrente da outorga de direito de uso das águas subterrâneas no Brasil

legal de estar o uso e manejo da água passível de limitações administrativas, sendo a outorga do direito de uso dos recursos hídricos uma garantia da aplicação do princípio da intervenção estatal compulsória.

Tal expediente, por sua vez, gera ao ente federativo a obrigatoriedade de cumprir uma série de encargos inerentes a sua natureza de promotor dos direitos fundamentais, inclusive o da proteção intergeracional do meio ambiente sadio e ecologicamente equilibrado a todos os partícipes do processo de fruição desses bens.

A finalidade dos encargos é integrar os usuários do processo de fruição no dever de zelo e conservação dos bens ambientais, sendo de todos os agentes envolvidos a responsabilidade de agir positivamente na defesa dos recursos hídricos (Costa Neto 2003).

$\mathrm{Na}$ definição de Costa Neto, as medidas de tutela podem ser entendidas da seguinte forma:

[...] as medidas de cunho positivo permeiam, por exemplo, o terreno da adoção de limitações administrativas ao exercício do direito de propriedade, do exercício do poder de polícia administrativa, da implementação de políticas públicas adequadas à promoção do meio ambiente sadio, da construção de um corpus normativo inspirado pelo valor ambiental agasalhado na Constituição e da atuação jurisdicional eficaz em relação à defesa do meio ambiente (COSTA NETO, 2003, p. 39).

Assim, não há que se falar em impropriedade na adoção da outorga de direito de uso para captação de águas subterrâneas para consumo humano, visto que é dever do Estado garantir os meios necessários de preservação dos recursos hídricos.

No mais, ressalta-se que a outorga de direito de uso em matéria ambiental foi delimitada pela colenda decisão como sendo instrumento da Política Nacional de Recursos Hídricos, que fixa sua natureza pública e tem como significado o entendimento de que "[...] o meio ambiente deve ser salvaguardado em nome e no interesse de toda a coletividade" (COSTA NETO, 2003, p. 49).

Dita característica autorizou o Tribunal Superior a julgar a causa priorizando o interesse público em detrimento do particular, haja vista tratar-se de direito difuso, que deve levar em consideração a essência transindividual e indivisível do acesso à água.

Portanto, a água deve ser disponibilizada para todos, em condições equânimes, antevendo-se, por meio do conjunto normativo específico, as metodologias regulatórias capazes de limitar o avanço das demandas individuais sempre que as causas coletivas forem postas em perigo de sucumbência. 


\section{CONSIDERAÇÕES FINAIS}

O cenário mundial de escassez da água é um fato cada vez mais acentuado, presente no centro das discussões relativas à preservação de bens de natureza ambiental. No contexto global ambiental, milhares de pessoas perdem a dignidade e até a vida por causa da falta desse recurso ambiental importante, necessário e vital.

Por essa razão, o direito a um meio ambiente ecologicamente equilibrado está intimamente ligado à questão do acesso ao bem ambiental água, tendo ele sido elencado no conjunto dos direitos fundamentais, integrantes do mínimo existencial inerente e extensível à humanidade.

Desse modo, a população em geral deve reconhecer o acesso equitativo à água como questão de política pública global prioritária. Além disso, o acesso a esse recurso deve ser entendido como política de estado reconhecida e aplicada pelos poderes públicos, nas esferas de competência nacional, regional ou local.

O Brasil, por ser considerado uma potência hídrica, precisa assumir posição compatível com as circunstâncias de esgotabilidade vivenciadas, de modo a salvaguardar para as presentes e as futuras gerações o gozo do direito a um meio ambiente integralmente equilibrado e sadio.

Em face desse cenário de possibilidade de escassez dos recursos hídricos, a finalidade deve ser a busca pela máxima tutela do bem ambiental em comento, mediante a adoção de políticas preservacionistas com a finalidade de regulamentação, inclusive a serem expandidas em prol da comunidade, em detrimento de interesses pontuais. $\mathrm{O}$ cuidado com a preservação deve ser o centro motivador das políticas públicas ambientais.

O Estado, mediante aplicação do princípio da intervenção compulsória em matéria ambiental, cumprindo sua missão regulatória, deve desenvolver, com base no arcabouço legislativo disponível, medidas de controle, gestão, monitoramento e fiscalização do uso e manejo das águas subterrâneas.

Para esse fim, deverá atuar diretamente nas outorgas e licenças preventivas através de controle prévio, ou seja, elas devem ser devidamente expedidas e supervisionadas pelas agências administrativas reguladoras correspondentes. É imprescindível, assim, o estabelecimento de prazo determinado e execução conforme os termos e condições do ato administrativo autorizativo.

Assim é que as providências administrativas, por reconhecerem a R. Fac. Dir. UFG, v. 41, n. 3, p.184-205, set/dez. 2017 
Preservação dos recursos hídricos e a limitação regulatória administrativa decorrente da outorga de direito de uso das águas subterrâneas no Brasil

esgotabilidade e limitação dos recursos hídricos, assegurarão, especialmente quanto à captação da água, o uso equitativo, cuja finalidade é impossibilitar a apropriação indevida para fins de acumulação de riquezas em prejuízo da coletividade.

No âmbito normativo, a regulação estatal relativa aos recursos hídricos deve empoderar-se de instrumentos de gestão de riscos, integrados com os demais mecanismos preventivos de prejuízos ou danos vindouros e assim proporcionar máxima efetividade aos recursos legais já existentes de proteção ambiental relativa aos recursos hídricos.

Necessário é também incentivar o desempenho sustentável da atividade econômica, de modo a evitar conflitos reais e também aparentes de interesses. É preciso que a mudança de paradigma se notabilize pelo predomínio consciente da normativa legal de proteção do recurso ambiental água.

Portanto, nesse novo paradigma é incompatível a postura individualista desrespeitadora do arranjo regulatório para a fruição dos recursos hídricos e, por via de consequência, desconhecedora da progressão das políticas públicas com viés de gestão e proteção baseadas no interesse coletivo de preservação do citado bem ambiental.

As dificuldades relativas à conciliação dos interesses individuais, econômicos, sociais e ambientais sempre foram enormes, mas compeliram o legislador a estabelecer limites preventivos para o uso, manejo e apropriação das águas subterrâneas.

$\mathrm{Na}$ esfera jurisdicional, os órgãos judicantes têm respondido à necessidade de proteção do bem ambiental de forma efetiva, atendendo aos anseios da coletividade. Nesse sentido, conclui-se que o Superior Tribunal de Justiça respondeu de forma a materializar as normas protetivas existentes, conciliando nos julgados de forma clara a opção de adaptar as atividades humanas aos limites da capacidade da natureza, determinando o impedimento da outorga de uso de água subterrânea em local já agraciado pela rede de abastecimento.

A bem-sucedida atuação jurisdicional na defesa do meio ambiente reflete a diretriz constitucional do caput do art. 225 , respondendo de modo direto ao aparente dilema entre o querer pontual e o dever coletivo. O entendimento jurisdicional assume caráter pedagógico em face de interesses de apropriação de riquezas e comportamentos rotineiramente individualistas de acumulação de recursos concedentes de estabilidade, facilidade e privilégio, em prejuízo do outro.

Os julgados trazem à análise a necessidade de ser cultivada uma consciência ambiental dotada de responsabilidade intergeracional e colocam em destaque a necessidade de se encontrar a alternativa mais viável ao problema do esgotamento dos 
recursos hídricos e da importância de sua conservação.

Tal arranjo é tarefa a demandar e envolver as funções de Estado em um só sentido, em que o Poder Judiciário, utilizando-se da ponderação de interesses, em última análise, dirime os conflitos aparentes entre direitos pretensos, assegurando a prevalência dos que se relacionem com o princípio das responsabilidades comuns e da preservação dos bens ambientais, de modo a agasalhar, com prioridade, o reconhecimento da supremacia do interesse de toda a coletividade.

\section{REFERÊNCIAS}

AGÊNCIA NACIONAL DE ÁGUAS - ANA. Relatório de conjuntura dos recursos hídricos de 2013. Brasília, DF: ANA. Disponível em: <http://arquivos.ana.gov.br /institucional/spr/conjuntura/webSite_relatorioConjuntura/projeto/index.html $>$. Acesso em:7 ago. 2017.

Relatório de conjuntura dos recursos hídricos de 2016. Brasília, DF: ANA, 2016a. Disponível em: <http://www3.snirh.gov.br/portal/snirh/centrais-deconteudos/conjuntura-dos-recursos-hidricos/informe-conjuntura-2016.pdf $>$.Acesso em:12 out. 2017.

. Coordenação de Outorga. Outorgas emitidas pela ANA. Brasília, DF: ANA, 2016b. Disponível em: <http://www2.ana.gov.br/Paginas/institucional/SobreaAna/ uorgs/sof/geout.aspx.>Acesso em:2 jul. 2017.

AMADO, Frederico. Direito ambiental esquematizado. 6. ed. São Paulo: Método, 2015.

BARBOSA, Erivaldo Moreira. Direito ambiental e dos recursos naturais: biodiversidade, petróleo e águas. Belo Horizonte: Fórum, 2011

BARROSO, Luís Roberto. Apontamentos sobre as Agências Reguladoras. In: Moraes, Alexandre de (Org.). Agências reguladoras. São Paulo: Atlas, 2002.

BRASIL. Constituição da República Federativa do Brasil de 1988. Brasília, DF: Senado Federal, 1988.

Lei n. ${ }^{\circ}$ 9.433, de 8 de janeiro de 1997. Disponível em:

<http://www.planalto.gov.br/ccivil_03/ leis/L9433.htm〉. Acesso em: 12 nov. 2017.

Lei n. ${ }^{\circ}$ 9.984, de 17 de julho de 2000. Disponível em:

<http://www.planalto.gov.br/ ccivil_03/leis /L9984.htm>. Acesso em: 12 nov. 2017.

Lei n. ${ }^{\circ}$ 10.406, de 10 de janeiro de 2002. Disponível em:

<http://www.planalto.gov.br/ccivil_03/leis/2002/L10406.htm.> Acesso em: 10 ago. 2017. 
Preservação dos recursos hídricos e a limitação regulatória administrativa decorrente da outorga de direito de uso das águas subterrâneas no Brasil

Lei n. ${ }^{\circ}$ 11.445, de 5 de janeiro de 2007. Disponível em:

<http://www.planalto.gov.br/ccivil_03/_ato2007-2010/2007/lei/111445.htm.>Acesso em: 7 jun. 2017.

Superior Tribunal de Justiça. Processo REsp no 518.744-RN. Primeira Turma. Rel. Min. Luiz Fux. Brasília, 2004. Disponível em: <https://www.jusbrasil.com.br/ jurisprudencia/busca?>. Acesso em: 7 jun. 2017.

Superior Tribunal de Justiça. Processo REsp 794.984/RJ. Primeira Turma.

Rel. Min. José Delgado. Brasília, 2006. Disponível em: <https://www.jusbrasil.com.br /jurisprudencia/busca?q=Primeira+ Turma+-

+Rel.+Min.+Jos\%C3\%A9+Delgado.>Acesso em: 12 nov. 2017.

Superior Tribunal de Justiça. Processo REsp no 1.345.403-RS. Segunda

Turma. Rel. Min. Francisco Falcão. Brasília, 2017. Disponível em:

<https://www.jusbrasil. com.br/jurisprudencia/busca?>. Acesso em: 2 nov. 2017.

CONSELHO NACIONAL DO MEIO AMBIENTE - CONAMA. Resolução no 396, de

3 de abril de 2008. Disponível em: <http://www.mma.gov.br/

port/conama/legiabre.cfm?codlegi=562.>Acesso em: 8out. 2017.

COSTA, João Vitor Menezes da e TYBUSCH, Jerônimo Siqueira. 2015. Uma abordagem crítica sobre a outorga dos direitos de uso dos recursos hídricos no Brasil. In: Fadisma, Santa Maria. Anais... Santa Maria. Disponível em: $<$ http://sites.fadisma.com.br/ entrementes/anais/wp-content/uploads/2015/08/umaabordagem-critica-sobre-a-outorga-dos-direitos-de-uso-dos-recursos-hidricos-nobrasil.pdf>. Acesso em: 12 nov. 2017.

COSTA NETO, Nicolao Dino de Castro e. Proteção jurídica do meio ambiente. i florestas. Belo Horizonte: Del Rey, 2003.

FERREIRA FILHO, Manuel Gonçalves. Reforma do Estado: o papel das agências reguladoras e fiscalizadoras. In: MORAES, Alexandre de (Org.). Agências

reguladoras. São Paulo: Atlas, 2002.

FIORILLO, Celso Antônio Pacheco. Curso de direito ambiental brasileiro. 13.ed. São Paulo: Saraiva, 2012.

MACHADO, Paulo Affonso Leme. Direito ambiental brasileiro. 17. ed. São Paulo: Malheiros, 2009.

ORGANIZAÇÃO DAS NAÇÕES UNIDAS. 2010. A ONU e a água. Disponível em: <https://nacoesunidas.org/acao/agua/>. Acesso em: 16 nov. 2017.

Declaração do Rio sobre Meio Ambiente e Desenvolvimento. 2012.

Disponível em: <http://www.onu.org.br/rio20/img/2012/01/rio92.pdf.>Acesso em: 12 set. 2017.

RIO GRANDE DO SUL. Tribunal de Justiça do Rio Grande do Sul. Recurso Especial 
$N^{\boldsymbol{o}}$ 1.345.403 - RS (2012/0197280-0). 2012. Relator: Ministro Francisco Falcão;

Disponível em: <http://direitoambiental.com/outorga-de-exploracao-de-poco-artesianoem-local-onde-ha-fornecimento-publico-de-agua-somente-e-possivel-para-finsindustriais-ou-para-uso-em-floricultura-ou-agricultura//.> Acesso em: 20 set. 2017.

SOUZA, Maurício Novaes. Impactos e externalidades socioambientais da construção de barragens e usinas hidroelétricas sobre comunidades e ecossistemas aquáticos. In:

Rezende, Leonardo Pereira e Dergan, Jorge Abdala. (Coord.). Proteção da

biodiversidade e construção de barragens hidroelétricas. São Paulo: Fiuza, 2012.

Artigo recebido em 15 de agosto de 2017 e aceito em 10 de dezembro de 2017

\footnotetext{
${ }^{1}$ Para a Organização das Nações Unidas (2010) a definição de consumo per capita é de 20 litros por dia, sendo que a fonte de abastecimento deve estar situada a distância não superior a mil metros.
}

${ }^{2}$ Relatório de Conjuntura dos Recursos Hídricos de 2013 e 2016, respectivamente, da Agência Nacional de Águas (ANA, 2013, 2016a).

${ }^{3}$ Amado (2015, p. 357) define a Agência Nacional de Águas como sendo uma agência: “[...] que atua como agente normativo e regulador do setor, vinculada ao Ministério do meio ambiente, com a função de implementar o Plano Nacional de Recursos Hídricos [...]”.

${ }^{4}$ Sobre o tema lecionou o professor Manuel Gonçalves Ferreira Filho (2002, p. 133): “[...] papel inerente a todo Estado é o controle das atividades individuais em vista do interesse geral. Mesmo no auge do liberalismo, no século XIX, não deixou ele de exercer essa função que é necessária para o bem comum $[\ldots .$.$] ".$

${ }^{5}$ Dentre as atribuições da citada agência, pode ser também do estado, garantir a universalização da oferta dos serviços de abastecimento de água, de modo a abarcar toda a parcela da população antes alijada do acesso a este bem ambiental (BARROSO, 2002).

${ }^{6}$ Arts. 1.288 a 1.296 do CC/2002. Esses artigos tratam do uso regular das águas existentes em nascentes em prédios particulares, não abordando a utilização de água extraídas do subsolo (BRASIL, 2002).

${ }^{7}$ Essa lei estabelece diretrizes nacionais para o saneamento básico, além de alterar as Leis 6.766/79, 8.036/90, 8.666/93 e 8.987/95 e revogar a Lei 6.528/78 (BRASIL, 2007).

${ }^{8} \mathrm{O}$ Direito enquanto ciência social aplicada visa reger e compatibilizar os desejos individuais e a vivência comunitária, circunstância que exige dos operadores e executores da ciência jurídica a necessidade de, continuamente, priorizar os aspectos e os fins que a sociedade julga mais relevantes, em detrimento de outros. A proposta de nação organizada, somente goza de 
Preservação dos recursos hídricos e a limitação regulatória administrativa decorrente da outorga de direito de uso das águas subterrâneas no Brasil

essencialidade se, para tanto, guardar pertinência entre seus princípios norteadores e as escolhas implementadas por aqueles que cuidam da gestão das políticas públicas, cujos efeitos devem ser experimentados por todos os componentes desta mesma nação.

${ }^{9}$ A Agência Nacional de Águas (2016b), em consonância com a definição contida na Instrução Normativa $\mathrm{n}^{\circ}$ 4, de 21 de junho de 2000, do Ministério do Meio Ambiente, conceitua a outorga de direito de uso dos recursos hídricos como sendo ato administrativo mediante o qual o poder público outorgante (União, Estado ou Distrito Federal) faculta ao outorgado (requerente) o direito de uso de recursos hídricos, por prazo determinado, nos termos e nas condições expressas no respectivo ato. $\mathrm{O}$ ato administrativo é publicado no Diário Oficial da União (no caso da ANA), ou nos Diários Oficiais dos Estados ou do Distrito Federal.

${ }^{10} \mathrm{O}$ artigo 1.291 do CC/2002 de forma abrangente já regulamentava o tema em comento nesses termos. (BRASIL, 2002). 